\title{
Does Language Contact Necessarily Engender Conflict? The Case of Cameroonian Quadrilingualism
}

\author{
Joseph Nkwain (Yaoundé)
}

\begin{abstract}
Cameroon proffers a propitious environment for the breeding of interesting linguistic phenomena that attract the curiosity of innumerable researchers. Its rich socio-cultural and linguistic background demonstrate a seemingly harmonious co-existence of two official languages English and French, a wide spread de jure lingua franca - Pidgin English and a myriad of about 266 Home Languages attest to the complexity inherent here. The co-existence of these languages, like in similar multilingual societies produces language contact situations such as code switching, interference, linguistic borrowing, diglossia, translation, etc., as users interact. This paper assesses language behaviour in such a complex multilingual setting where users adopt varying behavioural patterns leading to the production of interesting linguistic features and patterns worthy of investigation. Following Giles' Accommodation Theory and the descriptive and exploratory approaches, the paper accounts for and paints a vivid picture of the nature of language contact here, the consequences on the different languages and their users. It redefines conflict in relation to the socio-cultural and linguistic realities of this community. Drawing evidence from true-to-life situations, the paper establishes that if contact has to engender conflict, certain socio-cultural, political and linguistic forces related to attitudinal prejudices, unintelligibility, language policies, contextual clues, linguistic hostilities, etc., are likely to be responsible. It concludes with practical remedies like the redefinition of language policies based on the linguistic aspirations of speakers and the reconciliation of linguistic and political independence in order to carefully harness the linguistic resources of this crassly heterogeneous community.
\end{abstract}

\section{$1 \quad$ Introduction}

The present socio-historical and linguistic situation of Cameroon, a direct consequence of an accident of history, continues to fascinate keen observers. Strategically situated near Englishspeaking Nigeria to the west, French-speaking countries such as Chad to the north, Central African Republic to the east, Gabon, Congo, the Democratic Republic of Congo to the south and equally the Spanish-speaking Equatorial Guinea, the country enjoys in this positioning innumerable advantages. It is blessed with a rich sociolinguistic background (a myriad of about 266 Home Languages (HLs) (Ethnologue 2005), two official languages - English and French, a de jure lingua franca - Pidgin English (PE) and a hybrid code - Camfranglais.

The country proffers a propitious environment for the breeding of some interesting sociolinguistic phenomena that continue to attract researchers on several disciplines. The different people in this crassly multilingual and bi-cultural entity have been able to adopt peculiar communication strategies through which they effectively express their varying aspirations, feelings and daily experiences. The successful blending of a myriad of ethnic groups has been a laudable breakthrough in the search for a marriage of convenience in this bicultural setting. Today, the appellation "Africa in Miniature", referring to Cameroon, accurately attests to the rich socio-cultural and linguistic environment that underlies this community. However, 
against this seemingly discernible tranquility, exist inconveniences that members of the speech community as well as the authorities have to grapple with at different levels such as language planning policies, pedagogic exigencies, the harnessing of sociolinguistic diversities, etc. It is therefore against this backdrop of apprehensions that this study stems.

Languages do not meet but the users of the languages do meet. The contact of these languages through the users results in certain interesting phenomena such as code mixing, code selection, interference, borrowing, translation and interpretation, etc. Erstwhile statements by linguists viz: Weinreich (1953) Blom and Gumperz (1972), Ferguson (1972), Sankoff (1972), Kachru (1986), Bokamba (1989), Essein (1995), Jackson and Lang (1990), Nelde (1999), etc., have highlighted these aspects in their studies carried out in complex multilingual and multicultural communities.

This write-up attempts to investigate the question of language contact and conflict in a complex speech community - Cameroon. It exemplifies and attests to the contact and conflict situations and equally attempts to answer the question related to the possibility of avoiding contact and whether contact necessarily engenders conflict. It then determines the different implications of such situations on language behaviour. The paper finally makes suggestions for the way forward.

\section{Definition of Key Terms and Method Used}

Language contact here is viewed concomitantly with the definitions provided by the aforecited linguists. Contact accrues when two or more languages used in a specific speech community interfere, thereby, enhancing the occurrence of phenomena such as code mixing, code switching, borrowing, etc. The contact of languages through the users might not usually occur in a peaceful or harmonious manner due to varying degrees of tension, resentment and differences of opinion which characterise such communities, leading to conflict at various levels. Language conflict is construed here as a direct consequence of the language contact phenomenon and occurs whenever two or more languages compete for status. It is a predictable occurrence orchestrated by inherent pride, supremacy and a superiority complex expressed by the user of a language mindless of the linguistic legacy, aspiration and hegemony of the user of another language, raising problems ranging from intelligibility failure, apprehension, distrust, hatred and outright confrontation.

Cameroonian quadrilingualism refers to the use of two official languages - English and French - and a de jure lingua franca - Pidgin English - and Home Languages. This view neither relegates to the background nor underestimates the role of a vital linguistic resource such as Camfranglais (Ze Amvela 1983; Chia 1990; Kouega 2003) and other foreign languages taught in schools such as Italian, German, Arabic, Chinese and Spanish, which equally shape the linguistic behaviour of Cameroonians either directly or indirectly.

This write-up adopts Giles' Accommodation Theory which is socially diagnostic and lays emphasis on effective communication in complex multiethnic and multilingual communities. It is concerned with the way language users perceive and respond to language in such communities. The method involved an exploration of the language use situation in this complex community and makes an appraisal of the linguistic behaviour of speakers from different socio-cultural and linguistic backgrounds. The descriptive and exploratory approaches were adopted.

\section{Cameroonian Quadrilingualism: From Genesis to Current Trends}

Previous researchers have traced the socio-cultural and linguistic evolution of Cameroon viz: Mbassi-Manga (1973), Menang (1979), Mbangwana (1983), Todd (1991), Chumbow and 
Simo Bobda (1996), etc. The passage of each European power left indelible marks on the country's sociolinguistic landscape, some of which have outlived time. The present linguistic map of the country can generally be claimed to be an accident of the country's rich history.

Today, though Cameroon uses two official languages regulated by an official language policy that claims equity in status, the demographic imbalance, socio-political intricacies and ethnocentric complexes render the language policies inapt, in as much as a lot remains to be desired as far as effective implementation is concerned. Many tend to take recourse in advertent passive attitudes either characterised or reflected in the eccentricity that it is Cameroon (the country) which is bilingual and not Cameroonians.

The existence of a myriad of HLs for a population of about 19.5 million Cameroonians (2009 census) further complicates the whole situation. Despite incessant supplications of typologists aimed at seeing these languages revalorised and rehabilitated so as to readjust the linguistic status quo of the country (Ngijol 1964; Towa 1975; Tadadjeu 1975, 1983, 1978; Chia 1983; Alobwede 1999, etc.), the reticence and passive attitudes exhibited by authorities remain discouraging. However, despite the apprehension and passivity demonstrated, the languages continue to occupy an important place in the socio-economic, political and educational enhancement of the speakers. The insertion of some of the HLs into the school curriculum is no doubt an encouraging step towards their eventual recognition and officialisation.

The case of PE in Cameroon constitutes a tale marked by mixed feelings, scorn and indolence, just like what obtains in other communities where pidgins exist. Attitudes towards the language are reflected in declarations such as that of Wardhaugh (1986: 54) who asserts that "these languages have been considered not creative adaptations but degenerations, not systems in their own right but degenerations from other systems. Their origins have been explained not by historical forces but by inherent ignorance, indolence and inferiority". Such mixed feelings have been instrumental in shaping individual attitudes which can be summed up to constitute three different shades championed by advocates such as Chumbow and Simo Bobda (1996), Mbangwana (1983, 2004), Ayafor (2005) and Menang (2006), who, despite the misconstrued conception appended to the language, continue to advocate and showcase its vitality. There are mavericks in the likes of Kouega (2001) and Kfua (1996), who express a high sense of pessimism through a forecast of the eventual attrition of the language in Cameroon. Finally, there are moderates who recognise the legitimacy and importance of the language, yet, show some degree of reservation towards its use. These mixed feelings do not, however, lend the language a negative character, especially as it remains a veritable linguistic resource, an invaluable communicational tool worthy of protection and valorisation.

A description of the sociolinguistic situation of Cameroon remains incomplete if one sidelines a fast emerging and inevitable linguistic hybrid, which has come to magnify the complexity inherent here. Variously referred to as Camfranglais (Ze Amvela 1983; Tiayon 1985; Chia 1990; Mbah Onana 1994; Fosso 1996; Efoua-Zengue 1996; Essono 1996; Biloa 1999; Kouega 2003, etc.), this code has generally been described as an eccentric communicational tool, comprising a complex mixture of lexical items from English, French, PE and HLs. It is equally a speech reality especially in rapidly growing urban areas and registered in the speech habits of the youths. Its role in in-group communication is particularly noteworthy.

\section{$4 \quad$ Language Contact Patterns in Cameroon}

Language contact in Cameroon is an irrefutable reality. This takes place at different levels of language use and in different contexts as the various contextual variables come into play. As already been established, socio-cultural, political and historical trends were all favourable in the prevailing linguistic status quo evident in the country today. This could not have been possible if Cameroonians themselves were unable to accommodate the situation from the 
outset. Other factors have been instrumental in fostering the language contact situation such that we have the current trends. Apart from language planning policies, demographic, social ties such as inter-ethnic marriages, the language acquisition patterns of Cameroonians have greatly favoured the language contact situation in Cameroon.

Several surveys have demonstrated a great degree of variation in the patterns generally determined by the linguistic, socio-cultural and educational background of the individual. The patterns differ at individual levels and from place to place. Anchimbe (2006: 45) identifies the following acquisition patterns among Anglophones: HL + CPE + OL1 (+ OL2), CPE + HL + $\mathrm{OL} 1+\mathrm{OL} 2, \mathrm{HL}+\mathrm{OL} 1+\mathrm{CPE}$ (+ OL2), $\mathrm{CPE}+\mathrm{OL} 1+\mathrm{HL}+\mathrm{OL} 2, \mathrm{OL} 1+\mathrm{CPE}+\mathrm{HL}+\mathrm{OL} 2$, $\mathrm{OL} 1+\mathrm{OL} 2+\mathrm{HL}+\mathrm{CPE}$, with OL1 being English for Anglophones and OL2 being French for Anglophones and CPE stands for Cameroon Pidgin English. For Francophones, he identifies the following patterns: HL + OL1 + CPE (+ OL2), OL1 + HL + CPE + OL2, OL1 + $\mathrm{CPE}+\mathrm{HL}, \mathrm{HL}+\mathrm{CPE}+\mathrm{OL} 1+\mathrm{OL} 2$ and OL2 + OL1 + HL, with OL1 being French for Francophones and OL2 being English for Francophones. These patterns are significant to the status and functions of the languages and their necessity to each user. The patterns neither neglect the existence and acquisition of the foreign languages taught in schools and which further complicate the patterns. The above patterns not only demonstrate the bilingual and multilingual nature of Cameroonians, but, foster the language contact phenomenon as users interact. A critical survey of some of these situations of language use has enabled linguists to surface with phenomena that are characteristic of language contact situations such as code switching, code selection, code mixing, borrowing, translation and interpretation, etc., all manifest in the linguistic behavior of Cameroonians.

\subsection{Code Switching}

Code switching is typical of bilinguals and polyglots. It generally refers to a change from one code to another within the context of the same speech event. This is said to have occurred only when the user has made an initial code selection. To switch from English to French, English is supposed to have been chosen as the initial code. An overview of the language contact situation in Cameroon reveals the following possible switching patterns and vice versa in each case: $\mathrm{PE} \rightarrow \mathrm{F}, \mathrm{PE} \rightarrow \mathrm{E}, \mathrm{PE} \rightarrow \mathrm{HL}, \mathrm{F} \rightarrow \mathrm{E}, \mathrm{E} \rightarrow \mathrm{HL}, \mathrm{HL} \rightarrow \mathrm{HL}$, e.g., Ewondo $\rightarrow$ Eton, Douala $\rightarrow$ Bassa, Mungaka $\rightarrow$ Ghomala, etc. Again, the foregoing patterns do not sideline the presence and influence of other Foreign Languages (FLs) that equally condition switching making possible the following patterns and vice versa: $\mathrm{FL} \rightarrow \mathrm{PE}, \mathrm{FL} \rightarrow \mathrm{F}, \mathrm{FL} \rightarrow \mathrm{E}$, $\mathrm{FL} \rightarrow \mathrm{HL}, \mathrm{FL} \rightarrow$ FL, e.g., Spanish $\rightarrow$ German, German $\rightarrow$ Italian, etc. The absence of Camfranglais in the above combinations is explained by the composite nature of the language that exhibits a relatively high degree of admixture, its lexicon enriched by the process of borrowing and clipping of lexical items from these languages making it unalienable with the other languages.

The above patterns occur in multilingual settings where two or more languages are used. One is equally likely to witness switching in varieties of the same language as the case may be. Where PE has been considered as a variety of Cameroon English (CamE), a switch from PE to English demonstrates this pattern. This is more glaring when one considers switching in the different varieties like the six types identified by Mbangwana (2004: 27-35) viz: Anglophone Pidgin English (APE), Anglicised Pidgin English, (AnPE), Youth Pidgin English (YPE) or Jargon, Business Pidgin English (BPE), Creolised Pidgin English (CrPE) and Francophone Pidgin English (FPE). By virtue of this classification, one could readily envisage switching as follows: $\mathrm{APE} \rightarrow \mathrm{AnPE}, \mathrm{APE} \rightarrow \mathrm{YPE}, \mathrm{APE} \rightarrow \mathrm{CrPE}, \mathrm{APE} \rightarrow \mathrm{BPE}, \mathrm{APE} \rightarrow \mathrm{FPE}, \mathrm{AnPE} \rightarrow$ $\mathrm{YPE}, \mathrm{AnPE} \rightarrow \mathrm{CrPE}, \mathrm{AnPE} \rightarrow \mathrm{BPE}, \mathrm{AnPE} \rightarrow \mathrm{FPE}, \mathrm{YPE} \rightarrow \mathrm{CrPE}, \mathrm{YPE} \rightarrow \mathrm{BPE}, \mathrm{YPE} \rightarrow$ $\mathrm{FPE}, \mathrm{CrPE} \rightarrow \mathrm{BPE}, \mathrm{CrPE} \rightarrow \mathrm{FPE}, \mathrm{BPE} \rightarrow \mathrm{FPE}$. Be it vertical or horizontal types of switching (Ferguson 1972), situational or metaphorical code-switching (Blom/Gumperz 
1972), Nfonyam (1976) establishes that code-switching in Cameroon is determined by several variables such as solidarity, respect, distance and seclusion, topic, linguistic security, pride, stylistic variation, humour and connotation. Code switching therefore becomes an inevitable phenomenon when bilinguals and polyglots interact.

\subsection{Linguistic Borrowing and Interference}

Borrowing equally distinguishes itself as an inevitable language contact phenomenon and consists in the regular use of items and structures from the other language such that the borrowed items come to occupy an integral part in the lexical economy of the other language, acquired and used by the native speaker. These are therefore structures which have gained their lettres de noblesse in the lexical and semantic economy of the other language. Borrowing in the Cameroonian context exhibits a great degree of flexibility as the process is not unidirectional. This fluidity no doubt, contributes to the unintelligibility problems likely to occur when borrowed items are inappropriately exploited. Borrowing patterns are likely to be similar to code switching patterns earlier discussed as items borrowed cut across a broad linguistic spectrum. The following examples culled from Mbangwana (1989) and (1999), Anchimbe (2006), Ayafor (2006) and Echu (2008) are illustrative:

\begin{tabular}{|l|l|c|c|c|c|l|}
\hline \multirow{2}{*}{ Word } & \multirow{2}{*}{ Origin } & \multicolumn{3}{c|}{ Borrowing Languages } & \multicolumn{1}{c}{ Meaning } \\
\cline { 3 - 7 } & & PE & F & HL & CamE & \\
\hline aso & French associé & $\sqrt{ }$ & $\sqrt{ }$ & $\sqrt{ }$ & & client \\
\hline nyongo & Bamelike & $\sqrt{ }$ & $\sqrt{ }$ & $\sqrt{ }$ & & secret society \\
\hline ndole & Douala & $\sqrt{ }$ & $\sqrt{ }$ & $\sqrt{ }$ & $\sqrt{ }$ & a greenish bitter vegetable \\
\hline mbutuku & Jargon & $\sqrt{ }$ & & $\sqrt{ }$ & & a fool \\
\hline nkanda & Kikongo & $\sqrt{ }$ & $\sqrt{ }$ & $\sqrt{ }$ & & edible cow skin \\
\hline mukala & Douala & $\sqrt{ }$ & $\sqrt{ }$ & $\sqrt{ }$ & $\sqrt{ }$ & an albino \\
\hline mboh & Lamso & $\sqrt{ }$ & $\sqrt{ }$ & $\sqrt{ }$ & $\sqrt{ }$ & groundnut paste \\
\hline okro & Igbo & $\sqrt{ }$ & & $\sqrt{ }$ & $\sqrt{ }$ & slippery vegetable \\
\hline famlah & Bamelike & $\sqrt{ }$ & $\sqrt{ }$ & $\sqrt{ }$ & $\sqrt{ }$ & a mysterious death or secret sect \\
\hline eru & HL & $\sqrt{ }$ & $\sqrt{ }$ & $\sqrt{ }$ & $\sqrt{ }$ & a smallish vegetable \\
\hline gombo & Jargon & $\sqrt{ }$ & $\sqrt{ }$ & & & bribe \\
\hline Fon & grassfield HLs & $\sqrt{ }$ & $\sqrt{ }$ & $\sqrt{ }$ & $\sqrt{ }$ & traditional ruler in the grassfields \\
\hline Mallam & Fufulbe & $\sqrt{ }$ & $\sqrt{ }$ & $\sqrt{ }$ & $\sqrt{ }$ & head of Muslim community \\
\hline Kwifon & grassfield HLs & $\sqrt{ }$ & $\sqrt{ }$ & $\sqrt{ }$ & $\sqrt{ }$ & traditional council of elders in \\
grassfields
\end{tabular}




\begin{tabular}{|l|l|c|c|c|c|l|}
\hline scolarité & French & $\times$ & $\times$ & $\times$ & $\times$ & admissions office \\
\hline quartiers & French & $\sqrt{ }$ & $\sqrt{ }$ & $\sqrt{ }$ & $\sqrt{ }$ & residential area \\
\hline concours & French & $\sqrt{ }$ & $\sqrt{ }$ & $\sqrt{ }$ & $\sqrt{ }$ & competitive exam \\
\hline commissaire & French & $\sqrt{ }$ & $\sqrt{ }$ & $\sqrt{ }$ & $\sqrt{ }$ & superintendent of police \\
\hline caution & French & $\sqrt{ }$ & $\sqrt{ }$ & $\sqrt{ }$ & $\sqrt{ }$ & a deposit \\
\hline bon de caisse & French & $\sqrt{ }$ & $\sqrt{ }$ & $\sqrt{ }$ & $\sqrt{ }$ & pay voucher \\
\hline katika & Jargon & $\sqrt{ }$ & $\sqrt{ }$ & $\sqrt{ }$ & & controler of gamgling activity \\
\hline Nanga-mboko & Jargon & $\sqrt{ }$ & $\sqrt{ }$ & $\sqrt{ }$ & & a vagabond \\
\hline bonbons & French & $\sqrt{ }$ & $\sqrt{ }$ & $\sqrt{ }$ & $\sqrt{ }$ & sweets \\
\hline
\end{tabular}

Table 1: The interference and borrowing of some lexical terms.

The above table demonstrates the flexibility in the borrowing process as noticed in most items that almost cut across several areas of usage. Characteristic of these features is their propensity to represent socio-cultural values, features and realities that exhibit a national character, especially in terms of intelligibility, making them to enjoy wide spread. Equally worthy of note is borrowing from languages such as Portuguese, Yoruba, and Igbo. This corroborates the link with the socio-political, cultural and linguistic history of these languages and their users from the time of the first contacts of the indigenes with the Portuguese and their interaction with the various cultures in and around the country.

Borrowing is usually construed as similar to interference. To Mackey (1968), it refers to "those instances of deviation from the norms of either language which occur in the speech of the bilingual as a result of their familiarity with more than one language in contact, i.e., as a result of language contact". Interference is therefore, closely related to code mixing, which, unlike code switching which occurs at interlingual levels, occurs at the intralingual level. Elsewhere, it has been defined as the intrusion of single lexical items or structures of one language into another during a speech act. These intrusions are common and could be related to the patterns earlier identified with other contact phenomena. Common renderings such as the following are frequent in general use, especially among urban youths:

We now live in Bastos quartier.

'We now live in the Bastos residential area.'

Da crise économique di do all man.

'The economic crisis is touching everybody.'

Ton ami-ci me wonder, il aime trop le business.

'This friend of yours puzzles me, he adores fake dealings.'

Wul kah wu bu chuo kongku ki ta wu fu bribe.

'One cannot pass a competitive exam without giving bribe.'

The italicised items demonstrate interference at the lexical level as attested in the use of French quartier, in an English stretch, crise économique in a PE sentence, English wonder and business in a French text and kongku and bride in a HL (Bikom) sentence. Interference is more glaring in a typical Camfranglais text such as the following recorded by Biloa (1999: 147):

Je te chatch que le school est fort maintenant gars. Parce que le work que le prof nous gui est trop chap. Le mbom nous a largué one de ces interros, alors tu no que moi je suis debré car tu sais que si le school nous blo on le blo... 
'I tell you that school is difficult now because the work the teacher gives us is too difficult. The man gave us one of those tests, but you know that I struggled. As you know if school overcomes us, we overcome it too...'

The text above is an apt demonstration of the flexibility and creativity exhibited by speakers, especially the youths at the confluence of a myriad of different languages. In this hybrid, not only do we find the maintenance of the grammatical structure of English or French but what is particularly remarkable is the high degree of interference of lexical items from Pidgin English such as no (to know), from English language such as work and school and others from either a jargon or a HL such as chatch (to tell), chap (difficult), mbom (the man), débré, (struggled) and blo (to overcome).

\subsection{Translation and Interpretation}

When languages come into contact the inevitability of the problem of interintelligibility resurges. Among practical solutions, translating and interpretating have and continue to play a preponderant role in enhancing communication between members in a heterogeneous speech community. Translation is no doubt a complex linguistic enterprise with a dynamic dimension. To Nida/Taber (1962: 10), it consists in "reproducing in the receptor language the closest natural equivalent of the source language both in terms of meaning and style".

Despite the intricacies that underlie the art, the general tendency is the communicational intent that is satisfactory when mutual comprehension is attained. Interlingual and intralingual translation types are distinguished in Cameroon at various levels. At the official level, provisions have been made for translation from English to French and vice versa and this is done by trained translators from the Advanced School of Translation and Interpretation, Buea and from other private institutions. Interlingual translation takes these possible patterns and vice versa: $\mathrm{HL} \rightarrow \mathrm{F}, \mathrm{HL} \rightarrow \mathrm{E}, \mathrm{HL} \rightarrow \mathrm{PE}, \mathrm{HL} \rightarrow \mathrm{HL}, \mathrm{PE} \rightarrow \mathrm{F}$ and $\mathrm{E} \rightarrow \mathrm{F}$. These translations are evident in religious documents such as the Holy Bible, hymnals, simple prayer books, homilies, various tracts, flyers, signboards, posters, banners, logos, songs, films, etc., with each meant to serve particular communication purposes. Intralingual translation, referring to rewording something in the same language could take possible patterns such as $\mathrm{E} \rightarrow \mathrm{PE}$, $\mathrm{AnPE} \rightarrow \mathrm{BPE}, \mathrm{FPE} \rightarrow \mathrm{APE}$, etc.

Interpretation on the other hand is not an uncommon feature in language contact contexts. It generally has to do with making clear or showing the meaning of an utterance, a word or a symbol either in words or by artistic performance. In other words, it refers to an oral translation of words spoken in another language. It is meant to fill communicational gaps since interactants might not always share the same linguistic background. The patterns of interpretation in this context are similar to those identified under translation all depending on the context. It takes place during conferences, political and evangelisation campaigns, homilies, auction sales, political rallies, etc.

\subsection{Code Selection}

Another related aspect one often has to grapple with especially in multilingual settings is the choice of language for each speech event. This is particularly difficult given the complexity in the acquisition patterns, the domains of use (congruent and incongruent) and other deciding parameters. As such, several constraints come to play when the individual has to initiate a speech act. This is explicated by the fact that during the speech event, various factors are likely to intercede thereby influencing the turn of the event. Following observed scenes and inspired by Hymes' (1968) Ethnographic Approach to communication, extra-linguistic corelates such as the participants, the locale, the topic, the setting, role relations, the tone, the intention and pressure from parents can be held accountable for the choice of a code in such a 
multilingual setting. Linguistic co-existence in Cameroon is particularly intriguing as language behaviour tends to dismiss trends, suppositions and assumptions as users make use of the linguistic resources at their disposal.

From a subjective point of view, Cameroonian quadrilingualism is an asset. However, the undercurrents of such seemingly harmonious co-existence lay bear certain realities in this community as the different languages came into contact.

\section{From Contact to Conflict: Coping with the Question}

From the foregoing development, it becomes evident that language contact is a perfect reality in Cameroon. When languages come into contact, ramifications are inevitable and amongst them is conflict. Conflict has been redefined to refer to the race for status and recognition by two or more languages having related socio-cultural and linguistic implications on the language and users. In Cameroon, the race for linguistic supremacy by English, French, PE and HLs is on-going. Though placed on the same scale as French, English is far outweighed and its use and users continue to groan under the plight of consistent marginalisation in the different domains of use. The HLs are equally embarked in the race, firstly, among themselves and secondly, with the official languages. As some, especially those spoken by the ruling class are almost winning the race, the others still hope that in their HLs, they shall constitute a formidable force to reckon with at the national level.

The case of PE is particular as its high functional load and other comparable linguistic characteristics immediately qualify it as a potential winner in the race for status, yet, a deaf ear given to its plight, the lack of will and a rigid language policy are all militating to its disadvantage. Language contact therefore engenders conflict, in so far as the linguistic environment is particularly unenabling. There is the question of power which has to do with the ability of individuals or groups to realise their will in human relations, even against the will of others. As such, it provides answers to the question of whose interests will be served and whose values will reign. It is therefore against this backdrop of apprehension, struggle for supremacy and power that conflict at the linguistic level becomes inevitable.

\section{$6 \quad$ Language Conflict in Cameroon}

In his study of multilingual settings, Nelde (1990) identifies two types of conflicts which are equally evident in the Cameroonian context. There is natural conflict which emanates from a language contact situation pitting majority and minority language groups, with the minority group resisting all forms of assimilation, thereby, leading to conflict at various levels. Similar to the Canadian experience where the English-speaking minority resists the French-speaking majority, in Cameroon, the French-speaking majority exerts influence on the English-speaking minority, both at the socio-cultural and linguistic levels. The resistance of the minority groups is not, however, very much felt as seen in the prevailing trend characterised by the rush for English which will no doubt reconstruct the linguistic identity of the speakers in favour of the English language. The resistance is equally weakened by the linguistic processes such as code switching, code selection, code mixing, interference, translation and interpretation, borrowing, etc., which portray French as the absorbed code and English as the absorbing code. These processes weaken the resistance of the English language, though, they contribute in shaping language as it accepts new forms of expressions that enable users to be more expressive.

Artificial conflict arises from the situation of compromise where some languages are marginalised. This emanates from the situation of power struggle where the interests, will, aspirations and wellbeing of the speakers one language tend to reign at the expense of others. This is more intriguing when these languages are supposed to serve the interests of each 
language group equitably. This situation is prevalent in Cameroon as vividly depicted by Alobwede (1999: 184f.) in his observation that

In Yaoundé, the capital city of Cameroon, the natives who are now in power are outnumbered by other ethnic groups by almost 50-1. Yet in government and government officers, in the banking sector and in the military, they outnumber the other ethnic groups by almost the same ratio. With that strong presence in all strategic places, their language, Fang Beti (the lingua franca of three very near cognates, Bulu, Eton and Ewondo) has become the semi-official language of the city.

Usually, English for the most part and at times French, are relegated to the background as Fang Beti takes over as the language of governance, judiciary, banking, commerce and even evangelisation. This malaise has been recorded in other regions of the country where a handful of these indigenes are in positions of leadership. Here, they do not hesitate to hijack power through the use of a HL in the place of an official language which is abused like in the above manner. This causes resentment and disdain which, many at times culminate in outright physical conflict when co-participants disagree.

The above view does not however claim that in all language contact situations, conflict is bound to occur. In the case of Cameroon in particular, the sociolinguistic background of the country, the official language policies coupled with the uncompromising linguistic attitudes put up by speakers of certain languages towards others all favour conflict here.

\section{The Undercurrents of Cameroonian Quadrilingualism: Addressing the Polemics}

Previous studies such as Alobwede (1999), Mbangwana (1999), etc., attest to the language contact situation in Cameroon and the influence exerted by the French culture and language on English. This assimilation has left indelible marks on the linguistic performance of Cameroonians. This is through the embedding of linguistic elements from the two codes both intersententially and intrasententially. Contact, no doubt, portrays Cameroonian quadrilingualism as a resource, a repository of linguistic values that could breed greater unity in diversity if properly harnessed through planning.

There have been propositions and steps towards the establishment of a linguistic status quo favourable to each group of users, yet, these attempts and propositions have not been duly considered. The failure to harness the linguistic resources of the country has lead to a seemingly harmonious co-existence of languages which are for the most part geographically non-contiguous and genetically unrelated. This has lead to a situation of language use which emerges from conflicting poetics and thriving on assimilatory consciousness. This is evident in different controversial situations that emanate at the following levels of appreciation as Cameroonians interact.

\subsection{Biased Language Policies}

The country's constitution is particularly explicit on the language policy. Article 3 of part 1 of the 1972 Constitution states that the official languages of Cameroon shall be English and French, with both languages having the same status. Besides, the state shall guarantee the promotion of bilingualism throughout the country and shall endeavour to protect and promote national languages. This constitutional provision sounding quite promising, yet, unfulfilling continues to meet criticisms as a result of the failure to implement it. This does not however neglect or underestimate strides at various levels to implement these policies. The problem remains the lack of will, half-heartedness and bias involved in the implementation of the policy, which have all led to conflict at various levels.

Mbangwana (1999) after Chumbow and Simo Bobda (1995) vividly captures this intriguing situation in the demonstration of the gross imbalance in the production and distribution of 
official documents in English and French due to the influences exerted by French in political and administrative circles. They decry the absence of efficient policies that could stabilise the situation as in other multilingual settings. The situation is attested in documents exclusively in the French language such as most decrees appointing personnel in the different ministries, the writing scripts used in state universities, texts on the administrative and academic organisation of the University of Yaoundé I, texts related to the accreditation of elections observers, bank notes and coins, just to name these common examples.

This marginalisation is provocative as those supposed to use the documents are not always bilingual, thereby, leading to problems of misinterpretation and wrong appreciation of information. Even when an English version exists, the French version is highlighted, comes first and always in capitals. To further demonstrate this marginalisation, the French version of any translation is supposed to be more authentic in case of any controversy, as if to portray the French language as supreme.

Amidst this seclusion and marginalisation, many French speakers continue to take refuge in the naughty slang that it is Cameroon which is bilingual and not Cameroonians. This leaves the English speakers with resentment and frustration and their anger is usually expressed whenever and wherever need arises. Such situations demonstrate the conflictual roles of the official languages as one tends to override the other to the extend of performing some of the functions reserved for the other.

\subsection{Conflictual and Approximative Translations and Interpretations}

Translation and interpretation has earlier been highlighted as a remedy to intelligibility failure when interactants do not share the same code. This does not always work fully as certain variables may pose as hindrances especially in multilingual and bilingual contexts. A poor mastery of the target language can lead to approximative and conflictual renditions, especially where equivalents exist. Other factors such as pride, ambition, pomposity, ignorance, incompetence, intentional betrayal, etc., are likely to lead to such situations. The number of translators and interpreters who graduate from the training schools provide services limited to those in need of public services in ministries. The other millions of Cameroonians have to feign for themselves rather than wait for a one-to-one distribution of a speaker to a translator or interpreter. As they help themselves, stilted translations and interpretations are arrived at which create more confusion and misunderstanding. This situation is better captured in the popular anecdote the researcher obtained during an informal discussion forum during which participants exchanged short humourous tales. It is the case of a village interpreter who misinforms the christians because of his approximation of the preacher's message through a strictly literal interpretation and translation involving a HL - Bikom:

Preacher: Jesus came to the world.

Interpreter: Na Jesus ni gvi meyn iwundo.

'That Jesus came to the wall.'

Preacher: He brought us peace.

Interpreter: Wu gui meyn ni münju'.

'He brought urine.'

Preacher: He told us to be kind.

Interpreter: Wu bey meyn na ghesna na ghi kaynsi.

'He told us to be monkeys.'

Preacher: He told us not to be selfish to our brothers and sisters.

Interpreter: Wu bey meyn na ka ghesna na be'li shfisi.

'He told us not to be selling fish.' 
This misinterpretation arises from the confusion of HL words and the sounds of their English equivalents: world/wall, peace (interpreted as $\mathrm{CPE}$ piss)/urine, kind (taken for $\mathrm{HL}$ kaynsi)/monkeys and selfish/fish. The misinterpretation leads to a deceptive literal translation that betrays intended meaning.

Stilted translations have been responsible for controversial situations noticed in the usage of some Cameroonians. The following examples obtained from situations of general use and observation are illustrative. On the vehicle that transports school children, there are different inscriptions such as: School Bus, School Transport, Children's Transport, For School Children, etc., often translated as Transport d'Enfants, Bus Scolaire, etc., as the French equivalents. Similarly, on vehicles meant for the transportation of goods only, there are inscriptions such as Goods only and the equivalent being Passagers interdits. Others include certificate of non-conviction/casier judiciare, no urinating/ne pas uriner, no smoking/défence de fumer, no entry/pas d'issue, no jobs/pas d'embauche, etc. A more uncompromising example is the signpost indicating the delegation of national security. It reads: Délégation de la Sureté Nationale and translated as: The National Delegation for the National Security. This tautologious translation questions the translators' efficiency in the execution of their tasks. Other cases of conflict in translation have continued to intrigue keen observers because of the absence of equivalents and the need to come up with formal equivalents is still pressing. However, the Source Language and Target Language texts each tend to capture and express the particular reality in that context, reason why, each user tends to argue for the acceptability and legitimacy of a particularly equivalent. Where arguments are not convincing conflict is bound to ensue.

\subsection{Puritan Ethnocentrism}

Ethnologue (2005) spells out that 266 languages are attested in Cameroon. These languages are spread among the innumerable ethnic groups identified in the country. Here too, exist two distinct cultures. Cameroonians identify themselves within any of the ethnic groups, or share one of the two cultures either partially or fully. Issues of ethnic and cultural identity have constituted the main thrust in recent debates in Cameroon. Menang (2005) relates issues of cultural identity to all imaginable domains of human life, viz: publishing, media, religion, art, music, economics, science and technology, architecture, etc. Language is equally underlined as one of the principal elements which underlie one's identity. Speakers from different ethnic cleavages identify and react to certain linguistic elements which have particular connotations to them.

In the preservation of one's identity through a fervent linguistic hegemony, individuals tend to adopt puritan ethnocentric attitudes towards others. In this way, certain linguistic features become markers of the identity of particular individuals and groups and tampering with them through usage breeds animosity, contempt and even outright conflict. This becomes particularly grievous when these linguistic elements carry with them any negative connotation. Forms of expressions such as the following are illustrative especially when used provocatively: Anglo/anglofool (clip of Anglophone) refers to one who either does things ignorantly or who does not speak French fluently. Frog/francofool (clip of Francophone) refers to one who behaves foolishly or waywardly such as a francophone. Bamenda refers to one who is easily deceived. Bami (clip of Bamelike) refers to a person from the West Province noted for hard work and stinginess. Biafra refers to one from the English-speaking region or from Nigeria and likely to be involved in fraudulent activities. Dschang refers to a dirty person, a reflection of the filthiness exhibited by the pig, the main domestic animal in this region.

These ethnonyms, obtained from general use and observation, tend to carry invective connotations and are likely to engender conflict when evoked provocatively. This ethno- 
centrism is further demonstrated in the attitudes of francophones and anglophones who all hold steadfast to issues related to their identity. One of the contact tools through which the two cultures exhibit themselves remains language and they strive to uphold and preserve this legacy at all cost. This further explains why any act be it social, political or linguistic meant to jeopardise this resource meets with animosity and resentment.

Similarly, since language cuts across cultures, certain appellations tend to meet with mixed feelings when they are emitted with or without provocative intentions: Eboa and Kotto Bass, culled from the late Douala-based singers - Eboa Lotin and Kotto Bass who were lame, are used to refer to one who is physically handicapped. Ntufinga is used to refer to any pickpocket and culled from the act of stealing with the use of two fingers.

From the foregoing, one's socio-cultural and linguistic background can constitute a liability if jeopardised. At the same time, when cultures meet and the expression of these cultures takes place through language, one has to come to terms with socio-linguistic correlates that could either harness or create points of divergence.

\subsection{Linguistic Deculturation and Acculturation}

The pressure exerted by French on English has immensely contributed in structuring the socio-cultural and linguistic landscape. Mbangwana (1999) demonstrates how the two linguistic communities interact within and across each other in anglophone and francophone towns, especially at the administrative, communicative, educational and diplomatic levels. The diminishing proficiency in English language and the incessant spread of Pidgin English have all been contributory to the linguistic deculturation processes. The moulding of language into fresh shapes becomes inevitable, since French, English, PE and HLs used in these contexts do not exist in a vacuum. The languages are mutually interrelated and strongly affected by social, political, economic, cultural, and educational influences.

Unfortunately, but not regrettably, the influences are titled in favour of the French way of doing things, as felt at the military, cultural, educational and political levels. This tilt no doubt has a considerable bearing on linguistic behaviour. Mbangwana exemplifies these influences through illustrations with certain acronyms, female first names and word affixes. He equally notes that all these aspects provide "an effective channel for the passage of Gallicisms into CamE, thus, generating what has been felicitously referred to as Camfranglais" (1999: 93f.). It is in this similar way that new forms of expressions are inculcated into the other language, colouring and shaping usage.

Apart from some French-induced loan expressions like those earlier discussed, he equally provides examples involving morph-syntactic complexities exhibiting phrasal and sentential constructions based on similarities with French. The following examples culled from Mbangwana (ibid.) are illustrative. 


\begin{tabular}{|l|l|l|}
\hline \multicolumn{1}{|c|}{ French } & \multicolumn{1}{c|}{ CamE } & \multicolumn{1}{c|}{ BrE } \\
\hline assister & to assist somebody in hospital & to attend on somebody in hospital \\
\hline se presenter & to report somewhere for a matter & to call at a place for a matter \\
\hline de/à faire & help to do something & to help do something \\
\hline informer & to inform somebody & to tell somebody \\
\hline collectionner & to go collect something & to go and collect something \\
\hline avoir le regret d'annoncer & regrets to annonce & sorrowfully annonces \\
\hline dans le car & in the bus & on the bus \\
\hline
\end{tabular}

Table 2: Some French-induced expressions in CamPE

These examples demonstrate how the CamE speaker eventually produces structures related and induced from the French language to fill communication lapses during performance. The examples demonstrate how language contact leads to alteration and alternation, which both constitute the deculturation and acculturation of usage especially in Cameroon English. Each language tends to mould and give fresh shapes of meaning to equivalents and new linguistic experiences as users interact.

\subsection{Pedagogic Constraints}

For close to five decades, the struggle to instil English/French bilingualism and biculturalism in multilingual Cameroon as a step towards acquiring national unity through instruction in English and French has proven quite slow and wanting. The initial recognition of the role of language in education and development issues has been a first step towards the conception of an official language policy that constituted the background of pedagogic activities in the country. However, an evaluation of the progress in the implementation of the policies has revealed serious shortcomings and total lack of will in dealing with such essential issues as attested in Kouega (1999), MINEDUC (2000), Mbangwana (2002) and Fasse (2003). In such situations where there exist multiple and conflicting perspectives regarding the different language policies to suit the socio-cultural, linguistic and educational wellbeing of the citizens, there is need for overhauling attitudes and policies for greater chances of successful implementation.

The main thrust of the argument here lies on the implication of the language contact situation on the teaching, learning and use of language. Evidently, the language contact situation is bound to have serious ramifications on language behaviour. Though policies have concentrated and insisted on English/French bilingualism, the clarion call by optimistic linguists has been the review of the policies in favour of a place for the HLs and even PE in the school curriculum. Amidst the passivity in the implementation of these suggestions, policy makers continue to be rigid. However, the co-existence of the languages has ramifications at various levels.

First and foremost, the co-existence of English and French alongside a myriad of HLs, a de jure lingua franca - PE and other foreign languages, has real effects on the linguistic competence and performance of learners. As earlier demonstrated, this situation favours the deculturation and acculturation of the English language in Cameroon, justification, inter alia for the development of a non-native English variety - Cameroon English, just like other nonnative varieties which have developed elsewhere, thanks to contact with local environments 
(Kachru 1986). Like elsewhere, the debate has been rife as to the legitimacy, grammaticality and acceptability of these varieties.

More and more, the inability to come to a compromise and to reconcile the attitudes exhibited by the extremists has immensely contributed to the loopholes in the teaching, learning and use of some languages in Cameroon. Unlike in other exonormative cases where the society is strictly monolingual, the case of Cameroon is particularly unique as influences are from various directions. Equally, the absence of a regulatory body, such as the French academy to systematise language use, has, in no great measure, contributed to ameliorate the situation. Such deviations and/or innovations continue to widen the gap between learners, teachers and pedagogic inspectors who each have divergent views on the acceptability of deviations. However, in the absence of a regulatory force, the general tendency has been a favourable attitude towards the tolerance of a polymodel left to the teacher/examiner to assess the degree of acceptability based on the degree of approximation of the deviation and/or innovation.

The case of the inclusion of HLs and PE in the school curriculum has equally been pressing. The pedagogical implications are quite real and implementation equally poses problems at various levels. The question of trained personnel, pedagogic material, cost and primordially, the sensitisation of learners to understand and recognise the potential of these languages to their socio-cultural and linguistic evolution, constitute problems that have had to be grappled with. Furthermore, methodologies and appropriate approaches favourable to the teaching and learning of the languages constitute a condition sine qua non to an effective implementation of the policies. This initiative falls in line with the trilingual language policy (Tadadjeu 1983) that could be expanded to a quadrilingual language policy that entertains English, French, HLs and PE as equitable linguistic resources for all competent Cameroonians.

\subsection{Statutory Concerns}

The constitution is explicit on the linguistic situation of the country. Though the situation of English and French as official languages of the country needs to be redefined, it is evident that it remains officious. From every indication, the place of English in Cameroon is far less than an official language seen its deficient role in the administrative, educational, diplomatic, business, media and political circles. Just like the speakers, the language has been sidelined and mention of it is made only when official bilingualism is uttered, yet, at the level of implementation much remains to be desired. This situation has been decried and echoed by Ngangnang (1981: 30) when he observes that:

The pressure on Anglophones to learn and communicate in French far outweighs that of francophones to learn and communicate in English. While 75\% of anglophones in Yaoundé speak French daily, only $14 \%$ of francophones use English everyday... By sheer force of regular usage (even stilted loan translations, anglophones subconsciously and gradually undergo linguistic assimilation while simultaneously experiencing troublesome inroads upon their English.

Today, despite the above observation, the trend is the mad rush for the English language by the francophones though this still remains at the acquisition level. This rush has instigated projections tilted towards the reconstruction of a bilingual language policy exhibiting the tendency for francophones to acquire and use English to match their political and administrative superiority. In this way, French is likely to become the accepted code and English the accessible code used for communication across cultures. The English language at this juncture could then be felicitously referred to as a veritable national language with a true national identity. These projections equally take into cognizance the demographic factor as $80 \%$ of Cameroonians are French speaking and 20\%, English speaking. This representation does not however always paint a realistic picture of language acquisition and usage patterns. More than ever before, the rush for English by francophones and the subconscious 
assimilation of English speakers all call for a reconfiguration of the distribution of speakers of the languages based on competence and proficiency. In this way, an accurate and effective appreciation could be arrived at.

As English and French strive for recognition so too are the HLs and PE. Whereas the constitution makes allowances for the promotion of HLs which have for the most part remained an official declaration, no mention is made of PE. This shows the esteem in which these languages are held. Arguments for the development of a HL to serve national interests have been lumped as self-centred, unworkable and untenable to members of other linguistic groups who expect their language to be developed to a national standard. In this regard HLs such as Fufulde, Bassa, Mungaka, Beti, etc, which unsuccessfully vied for this enviable status have all resigned to serve their different ethnic group interests. Today, rather than empowering one to enjoy official status at the expense of others, an objective and comprehensible trend should be the insistence on the development of all the languages thereafter according them same status. This measure could help contain the endemic tribalistic tendencies exhibited by certain ethnic groups especially those from which most of the ruling class emanates. The use of Ewondo, Eton and Bulu languages in administrative, political and educational circles leaves an onlooker with the impression that these were semi-official languages.

The situation of PE is seemingly pathetic, yet, an $\mathrm{x}$-ray of the realities underlying this resource warrants its propulsion to a national language. Statements related to the language such as Kisob (1963), Menang (1979), Tiayon (1985), Ayafor (1986) and (2006), Ngome (1986), Todd/Jumbam (1992), Mbangwana (1983, 2004), have revealed the potential of this code as an invaluable linguistic weapon worthy of recognition and standardisation so that it could vie for the status enjoyed by English and French. Its role in mass communication, evangelisation and political campaigns, electioneering, commerce, illiteracy campaigns, etc., all attest to its high functional load. The question of its spread and use is no longer a cause for concern as its tentacles have fast invaded the nooks and crannies of nearly all Cameroonian societies (Koenig et al. 1983). More studies such as Menang (1979), Ngome (1986), Ayafor (1986), Todd/Jumbam (1992) have all revealed the morphosyntactic and lexical processes which make the language an independent linguistic entity with characteristic features similar to those exhibited by fully-fledged languages and as such should be equated with them at the different levels of comparison. The writers above realise in the language potentials that justify and quality the language for a place in the race for official recognition. They therefore argue that if the language was fully developed through a systematic writing convention and pronunciation, standardised and promoted both at local and national levels, it could serve as a strong official language more than English and French. Though these remain speculations and projections, their implementation should be against a backdrop of optimism rather than apprehension.

\section{On the Possibility of Avoiding Conflict}

That languages in multilingual contexts must come into contact is an undeniable assumption. That contact leads to conflict is a reality, yet, avoiding conflict is another question that has to be grappled with. How then could conflict be avoided if it is inevitable and where inevitable, how could it be managed?

Firstly, issues related to nationhood, nation building, nationism and national integration are all dependent on the strong political will of the citizens. It all stems from a positive appreciation of the political independence of the citizens. At the same time, political independence without linguistic independence is a farce. Linguistic independence here refers to a redefinition of the language policies based on the practical realities which are favourable and evident to all users 
mindless of their linguistic or ethnic backgrounds. It is only when each speaker enjoys the freedom to use language without necessarily infringing on the linguistic rights of the other speaker do we attain such an objective.

The exercise of flexible ethnocentric attitudes towards the sociolinguistic rights of others is a step towards the achievement of this linguistic independence. This, amongst other things like, the realisation that the words "anglophone" and "francophone" constitute notions whose definitions are subjected to contextual realities and are likely to spark flames of animosity when they are misinterpreted or evoked with invective connotations. For purposes of clarifications, for example, anglophones do not constitute an ethnic group but a community of people definable in terms of certain notions and markers such as those outlined by Menang (2006) including: geographical and historical background, English inspired education, life style features and character features. A harmonious and careful reconciliation of these notions constitute a stepping-stone towards conflict resolution.

On the other hand, as English and French vie for supremacy as witnessed in status conflict between the two languages, the creation of a buffer language to serve a tension reduction purpose is thought worthy. This could be chosen and implemented either at the official or individual level as the immediate context warrants. PE could effectively serve such a purpose seen its spread, high functional load and adaptable linguistic characteristics. In this case, conflicting parties could resort to PE in situations of intelligibility failure when neither English nor French is able to serve the communicational aspirations of the interactants. In this way, code switching becomes a remedial process that eventually eases tension and creates harmony both amongst users and languages.

\section{Conclusion}

This write-up has attempted to address some of the realities inherent in a crassly multilingual setting like Cameroon. It has equally demonstrated the manifestations of certain phenomena when languages come into contact. They have been exemplified through processes such as code switching, code mixing, interference, borrowing, code selection, translation and interpretation. The paper established that unlike in other contact contexts where conflict can be evitable through the respect of established linguistic policies and flexible attitudinal patterns, in the Case of Cameroon, conflict is inevitable and this is favoured by factors such as biased language policies, conflictual and approximative translations and interpretations, puritan ethnocentrism, linguistic deculturation and acculturation of languages. Furthermore, it insinuated that contact breeds certain ramifications especially at statutory and pedagogical levels where official language polices do not take care of the linguistic realities of the community such that the teaching, learning and use of language become a nightmare. The paper went ahead to examine the types of language conflict in Cameroon and identified two types - natural and artificial conflicts which were both exemplified. It then asserted that conflict is an inevitable consequence of the language contact phenomenon and though it could serve as a resource when carefully harnessed, it could still constitute the origin of outright physical conflict which could however be avoided through contextual redefinition of certain problematic notions, the exercise of flexible ethnocentric attitudes and above all blending political independence with linguistic independence.

\section{References}

Alobwede d'Epie, Charles (1999): "African Indigenous Languages as Semi-Official Languages". In: Echu, George/Grundstrom, Allan (eds.): Official Bilingualism and Linguistic Communication in Cameroon. New York: 175-186. 
Anchimbe, Eric (2006): Cameroon English: Authenticity, Ecology and Evolution. Frankfurt a. M.

Ayafor, Miriam (1996): "An Orthography for Kamtok: A Proposal for a Standard Script for Cameroon Pidgin English". English Today 12/4: 52-57.

Ayafor, Miriam (2006): "Kamtok (Pidgin) Is Gaining Ground in Cameroon". In: Chia, Emmanuel N. (ed.): African Linguistics and the Development of African Communities. Oxford: 191-199.

Biloa, Edmond (1999): "Structure Phrastique du Camfranglais: Etat de la Question". In: Echu, George/Grundstrom, Allan (eds.): Official Bilingualism and Linguistic Communication in Cameroon. New York: 147-174.

Blom and Gumperz, John (1972): "On Social Meaning in Linguistic Structures: Codeswitching in Norway". In: Gumperz, John/Hymes, Dell (eds.): Directions in Sociolinguistics: The Ethnography of Communication. New York: 407-434.

Chia, Emmanuel N. (1983): "Cameroon Home Languages". In: Koenig, Edna et al. (eds.): A Sociolinguistic Profile of Urban Centers in Cameroon. Los Angeles: 144-152.

Chumbow, Beban S./Simo Bobda, Augustin (1996): "The Life Cycle of Post-Imperial English in Cameroon". In: Fishman, Joshua et al. (eds): Post-Imperial English: Status Change in Former British and American Colonies 1940-1990. Berlin: 401-428.

Echu, George (2008): "Forms of Address as a Politeness Strategy in Cameroon Pidgin English". In: Mulo Farenkia, Bernard (ed.): Linguistic Politeness in Cameroon. Frankfurt a. M.: 121-133.

Ethnologue (2005): Languages of the World. Available at http://ethnologue.com, retrieved 01/09/07.

Hymes, Dell (1968): "The Ethnography of Speaking". In: Fishman, Joshua (ed.): Readings in the Sociology of Language. The Hague: 99-133.

Kachru, Braj (1986): The Alchemy of English: The Spread, Functions and Models of NonNative Englishes. Oxford.

Kfua, Bony (1996): "Time is up for Pidgin English". The Herald 359: 20-22.

Koenig, Edna et al. (eds.) (1983): A Sociolinguistic Profile of Urban Centers in Cameroon. Los Angeles.

Kouega, Jean Paul (2001): "Pidgin Facing Death in Cameroon". Landscape 21: 11-22.

Mackey, Williams (1968): "The Description of Bilingualism". In: Fishman, Joshua (ed.): Readings in the Sociology of Language. The Hague: 554-584.

Mbangwana, Paul (1983): "The Role and Scope of Pidgin English in Cameroon". In: Koenig, Edna et al. (eds.): 144-162.

Mbangwana, Paul (1989): "Flexibility in Lexical Usage in Cameroon English". In: Garcia, Ofelia/Otheguy, Ricardo (eds.): English Across Cultures, Cultures Across English. Berlin: 319-333.

Mbangwana, Paul (1999): "The Linguistic Deculturation of English in Cameroon". In: Echu, George/Grundstrom, Allan (eds.): Official Bilingualism and Linguistic Communication in Cameroon. New York: 87-111.

Mbangwana, Paul (2004): "Pidgin English in Cameroon: A Veritable Linguistic Menu". In: Echu George/Gyasi Obeng, Samuel (eds.): Africa Meets Europe: Language Contact in West Africa. New York: 23-44.

Mbassi-Manga, Francis (1973): "English in Cameroon: A Study in Historical Contact, Patterns of Usage and Current Trends". Unpublished Ph.D. Thesis, University of Leeds.

Menang, Thaddeus (1997): "Trends in Cameroon Pidgin English Lexicology: A Study of Anglophone Speech". Unpublished M.A. Dissertation, University of Yaoundé.

Menang, Thaddeus (2005): "Pidgin English and the Anglophone Identity in Cameroon". Paper presented during the International Conference on Language, Literature and Identity, University of Yaoundé 1. 
Nelde, Peter (1997): "Language Conflict". In: Coulmas, Florian (ed.): The Handbook of Sociolinguistics. Oxford: 285-300.

Newmark, Peter (1985): Approaches to Translation. Oxford.

Nfornyam, Joseph (1976): "Code Selection: A Study of Language Usage Among Bilingual Students of the Faculty of Letters, University of Yaoundé". Unpublished Maitrise Dissertation, University of Yaoundé.

Ngangnang, Jean (1981): "Cameroon Official Bilingualism Out of Focus?" Unpublished Maitrise Dissertation. ASMAC. University of Yaounde.

Nida, Eugene/Taber, Charlse (1962): The Theory and Practice of Translation. Leiden.

Simo Bobda, Augustin (1994): "Lexical Innovation Processes in Cameroon". World Englishes 13/2: 245-260.

Simo Bobda, Augustin/Wolf, Hans G. (2003): "Pidgin English in Cameroon in the New Millenium". In: Lucko, Peter et al. (eds.): Studies in African Varieties of English. Frankfurt: $101-117$.

Tadadjeu, Maurice (1975): "Language Planning in Cameroon: Toward a Trilingual Education System". In: Herbert, Robert K. (ed.): Patterns in Language, Culture and Society: SubSaharan Africa. Ohio: 53-75. (= Working Papers in Linguistics 19).

Tadadjeu, Maurice et al. (1978): Propositions pour l'Enseignement des Langues Camerounaises. Yaoundé.

Tadadjeu, Maurice (1983): "Prospects for Language Planning Studies in Cameroon". In: Koenig, Edna et al. (eds.): A Sociolinguistic Profile of Urban Centers in Cameroon. Los Angeles: 117-124.

Tiayon, Lekobou (1985): "Camspeak: A Speech Reality in Cameroon". Unpublished Maitrise Dissertation, University of Yaoundé.

Todd, Loreto (1991): Pidgins and Creoles: A Structured Course in West African Pidgin English. Leeds: Tortoise Books.

Todd, Loreto/Jumbam, Martin (1992): "Kamtok: An Anatomy of a Pidgin". English Today 8/2: 3-11.

Wardaugh, Ronald (1986): An Introduction to Sociolinguistics. Oxford.

Wardaugh, Ronald (1987): Languages in Competition: Dominance, Diversity and Decline. Oxford.

Ze Amvela, Etienne (1983): "English and French in Cameroon: A Study in Language Maintenance and Shift". In: Echu, George/Grundstrom, Allan (eds.): Official Bilingualism and Linguistic Communication in Cameroon. New York: 133-145.

Ze Amvela, Etienne (1983) "The Franglais Phenomenon: Lexical Interfernce and Language Mixing in the United Republic of Cameroon". Bulletin de l'AELIA 6: 419-429. 